\title{
OVERSEAS DEVELOPMENT AND SERVICE BILL
}

$\mathrm{T}$ HE Overseas Development and Service Bill had an unopposed second reading in the House of Commons on February 24. The Minister of Overseas Development, Mrs. B. Castle, claimed that the Bill reflected the spirit of the discussions of the United Nations Conference on Trade and Development, and in moving its second reading explained that Clause 1 would assist good planning of colonial development and welfare by providing a year's overlap. Under this Clause, a further $£ 50$ million was provided for schemes financed by grants, and a further $£ 20$ million for loans, which with the outstanding amounts gave totals of $£ 95$ million for grants and $£ 40$ million for loans for the five years up to 1970 , for a much smaller number of dependent territories than was covered by the $£ 68.5$ million and $£ 32$ million, respectively, provided for the three years 1963-66 under the 1963 Act. About thirty Governments still came within the scope of the Colonial Development and Welfare Acts, but Mrs. Castle thought it unlikely that actual expenditure would reach the ceiling of $£ 25$ million for grants for the first three years or $£ 10$ million for loans. The Bill also lowered the proportion of loans to grants and provided 70 per cent of this aid in grants, and she hoped to see the aid given in a form in which it could be speedily used for develop. ment.

Clause 2 of the Bill extended the provisions of the Overseas Service Act, 1961, which it replaced, under which 41 Governments and administrations had entered into agreements, and during the present year more than 11,000 officers were receiving benefits at a cost to the British Government of more than $£ 16$ million. During 1964, nearly 1,800 officers had been recruited by the Ministry and requests were still increasing. So far, the scheme had been limited to officers in the central public services of overseas Governments who were expatriate members of the Overseas Civil Service or expatriate contract officers appointed in the same way. Under this
Clause, the Minister was authorized, with the agreement of the Treasury, to extend the scheme to bodies and organizations overseas other than Governments who were employing expatriate officers, and to public or social services such as education or local government. Mrs. Castle said that while no general offer of help would be made, she would consider any requests which might be received on their merits. At the third Commonwealth Education Conference at Ottawa in August 1964, financial assistance had been offered towards the salaries of British teachers in overseas universities, and Mrs. Castle said she proposed to honour this undertaking through the extension of the aid scheme if the Bill were passed. She also emphasized that under the present scheme Britain had been at pains not to disturb the relation between overseas Governments and the expatriate officers they employed or to encourage any division of loyalty: she believed that this principle was right. Finally, she stressed the importance of enlarging and improving Britain's technical assistance.

The Bill was generally welcomed in a well-informed debate, and in winding up for the Government, the Parliamentary Secrotary to the Ministry of Overseas Development, Mr. A. E. Oram, said that whereas under the 1963 Act $£ 109$ million was provided over three years for a population of 18.75 million, under the present Bill $£ 135$ million over five years was made available for 5.5 million. In a written answer on the same day, Mrs. Castlo stated that bilateral economic aid to developing countries disbursed by the Government in 1963 amounted to $£ 69.2$ million in grants and $£ 69.7$ million in loans; for 1964 the corresponding figures were $£ 81.9$ million and $£ 92.5$ million. In addition, $£ 13.3$ million in 1963 and $£ 13$ million in 1964 wore contributed in multilateral aid to international organizations and $£ 5.7$ million and $£ 3.0$ million, respectively, in multilateral aid in other ways. In 1963 private investment contributed about $£ 65$ million.

\section{PROBLEMS IN SETTING UP NEW UNIVERSITIES}

\begin{abstract}
A PAPER, The Creation of New Universities *, has been prepared by Dr. C. I. C. Bosanquet and Mr. A. S. Hall, based on a conference held at the University of Keele in July 1964. The conference was attended by representatives of all the existing new universities, and its purpose was to assess experience in planning, their physical layout and their academic strategies. Moreover, it was hoped that it would indicate the distinctive features of the British contribution to thought and design, and the common features of the technique used in establishing new universities and of the public pressures they illustrate. By and large, the authors conclude that disappointingly little use has been made of the opportunity for innovation. While the new universities are being created with remarkable speed and administrative skill, the range of subjects and types of teaching offered are unlikely to be altered significantly, but the kind of education hitherto confined to Oxford and Cambridge would be more widely distributed in the United Kingdom.

The sites so far chosen, with the exception of Warwick, lie on previously undeveloped land near the outskirts of towns of medium size, usually of historic interest, lacking major industry, but centres of local administration. The

The Creation of Nero Universities. (Based on a Conference at the University of Keele, July 14 to 16, 1964.) By 1 .
Hall. Pp. (Keele: The University, 1964.)
\end{abstract}

older industrial areas, as a rule, have failed even to create a 'promotions committee'. The form of constitution evolved does not differ significantly from the constitution of twenty universities that have $\operatorname{come}$ into being in Britain since 1890. No daring experiments have as yet been tried-the main reason for this is regarded as being money: no university foels it can be independent of some kind of local support.

The four formal sessions of the conforence covered the shaping of university development plans; curriculum and teaching; staff and student residential arrangements and social life; academic organization and university government.

While there was some sharp difference of opinion over internal organization, such as the extent to which it should centre on the college system or around schools of study, how far a university should impose its guardianship on its students, the degree of responsibility exercised by the University Grants Committee in regard to subjects of study and the relation of universities to Parliament, there were two main points of agreement. First, in development, strategy as well as tactics must be subject to continuous review, taking into account experience gained by the individual university, overall national needs, and the availability of reserves. Secondly, the greatest single difficulty has been inadequate reserves during the planning 
period. The policy of the University Grants Committee to make no recurrent grants until a university receives its first students has postponed the appointment of key academic staff and necessitated the taking of decisions affecting the shape of a university for years to $\operatorname{come}$, without the benefit of continuous academic advice. The very short period in advance for which capital grants have been indicated has also delayed physical planning, and while it is essential that a new university should be assured of the sums of money that may be committed over each of the next five years, it would be still more helpful to indicate capital grants for ten years ahead. This financial assurance would also assist the start of the scholarly and scientific work of the university.

\section{REPRODUCTION OF THE AFRICAN ELEPHANT}

\begin{abstract}
CONTINUING his researches on the reproduction of $\checkmark$ the African elephant, Dr. J. S. Perry has examined eight foetal specimens collected during a two-year stay in Uganda*. In one paper Prof. E. C. Amoroso and Dr. Perry have investigated the foetus in utero in a series ranging from the smallest, weighing only $2 \mathrm{~g}$, to a nearterm male of $120 \mathrm{~kg}$. Adequate preservation in the field enabled the authors to describe not only the gross structure of the foetal membranes, but also the microscope anatomy of the placenta. Tho placenta of the elephant is zonary, but the allanto-chorionic villi are thinned or interrupted at intervals on the circumference of the chorionic sac. The large allantois is quadrilocular; its four sacs completely separate amnion and chorion, fusing with the former and meeting over the back of the foetus. A yolk sac was present in the youngest foetus of approximately two months gestation. The endodermal lining of the allantois bears a large number of mushroom-shaped "allantoic pustules" of unknown function.

The placenta is of the vaso-chorial type of Amoroso and Wislocki. The single-layered trophoblast is partly cellular and partly syncytial. Marginally maternal blood

* The Foetal Membranes and Placenta of the African Elephant (Loxodonta africana). By E. C. Amoroso and J. S. Perry. The Structure and Develop Perry, Phil. Trans. Roy. Soc., B, 248, 1, 35 (1964).
\end{abstract}

\section{CHEMISTRY AND PHYSIOLOGY OF 'DORMINS' IN SYCAMORE}

\section{Identity of Sycamore 'Dormin' with Abscisin II}

CROWTH-inhibitory compounds ('dormins') play a $J$ part in the regulation of bud-growth of some woody perennials ${ }^{1-5}$. In sycamore and in birch, a change from long-day to short-day conditions produces a marked increase in dormin concentration and the buds stop growing; dormin-containing extracts of leaves from birch plants grown under short-day conditions inhibit the growth and induce the formation of resting buds in actively growing birch seedlings maintained under long-day conditions. Owing to the considerable technical difficulties attending the determination of bud-inducing activity, concentration of dormin is usually estimated by inhibition of wheat coleoptile growth.

On the other hand, Addicott et $a l .^{6,7}$ have isolated a plant hormone (abscisin II) from young cotton fruit by following its abscission-accelerating effect in cotton explants. Abscisin II was also found to inhibit oat coleoptile growth ${ }^{6,7}$. We have isolated the dormin from sycamore (Acer pseudoplatanus, L.) in crystalline form and have established its identity with abscisin II.

Chopped, dried sycamore leaves, collected in the autumn of 1963 , were extracted at $4^{\circ}$ with $4: 1(\mathrm{v} / \mathrm{v})$ methanol : water. The methanol was removed under reducod pressure; the residual aqueous solution, decanted from the precipitated chlorophyll and acidified to $p H$ 3.5 , was extracted with ether. The dormin was extracted from the ethereal solution into aqueous sodium bicarbonate; continuous ether-extraction of the bicarbonate solution, adjusted to $p \mathrm{H} 8 \cdot 0$, removed most of the weakly exudes and is ingested by the cytotrophoblast. Centrally on the placental band active phagocytosis occurs. The elephant, hyrax and manatee "share a number of features in the arrangement of the foetal membranes and in the detailed structure of the placenta". Fourteen half-tone plates illustrate the work.

In the second paper, which is an extension of that published in 1953, Dr. Perry describes the reproductive organs of the female African elephant in foetal and young animals. The remarkable feature of the external genitalia is the similarity between male and female, in that the urogenital canal has been carried forward on the belly of the female to a point close behind the umbilicus, to a position similar to that of the male opening. The uterine horns undergo a ram's horn flexure, as in some ungulates, before uniting to form the body of the uterus, but the lumina remain separate for most of its length, and it is here that a one-sided conception occurs. The muscles of the external portion of the female genitalia are described. There are four plates of photographs of dissections and transverse sections of the reproductive tract, and seventeen text figures.

These papers give us for the first time a clear picture of the foetal membranes and placenta of the African elephant. acidic inactive compounds; subsequent acidification to $p H \mathbf{H} \cdot 5$, ether-extraction, and evaporation of the ethereal solution yielded a rancid-smelling gum containing the dormin. This was dissolved in a slight excess of aqueous sodium hydroxide and treated with aqueous lead acetate which precipitated much inactive material, but left dormin in solution, from which it was extracted with ether after acidification. Further purification was by column chromatography (silicic acid, eluted with benzeno-other mixtures) followed by thin-layer chromatography ('Kieselgel-(G'), developed with a propanol-butanol-ammoniawater $(6: 2: 1: 2 \mathrm{v} / \mathrm{v})$ mixture. This gave a colourless partly crystalline gum, recrystallization of which from benzene yielded $260 \mu \mathrm{g}$ of the dormin as minute platelets, m.p. $\sim 160^{\circ}$ (Kofler block), which sublimed at $\sim 130^{\circ}$ in a high vacuum. For abscisin II, Addicott et al.$^{6,7}$ give m.p. $160^{\circ}-161^{\circ}$, subl. $120^{\circ}$.

Inhibitory activity was followed by germinating excised wheat embryos ${ }^{8}$ for $48 \mathrm{~h}$ at $27^{\circ}$ in the dark in $0.01 \mathrm{M}$ sodium phosphate buffer ( $p \mathrm{H} 7.4$ ) containing the test material at five or more geometric dilutions. Probit percentage reductions in coleoptile length were plotted against $\log _{10}$ concentration to give a straight line. The concentration reducing length by 50 per cent was used to compare the activities of the test material. We have detected only one compound showing high growth-inhibitory activity in sycamore leaves.

The molecular weight of the dormin, determined by mass-spectrometry, was 264 , identical with that reported ${ }^{6,7}$ for abscisin II. The infra-red spectrum (potassium 